\title{
Study on College English Teaching Reform in the Age of Artificial Intelligence
}

\author{
Yingchun Zhang ${ }^{1, *}$ \\ ${ }^{1}$ College English Teaching Department of Zaozhuang University, Zaozhuang, Shandong 277160, China \\ *Corresponding author. Email: Zhangyingchun1981@163.com
}

\begin{abstract}
College English has always been a subject with low dependence on technology. With the great development of artificial intelligence technology in the field of natural language, English teachers in college must solve the problem of their objective abilities and seek to form a learning community which helps to improve their development capabilities through the integration of cultural courses and specialized courses. English teachers in college also need to unite their students, shift their thinking and optimize teaching model in a wider range. Through the integration of tools and the design of forms, College English teaching will step into the era of artificial intelligence, and the quality of College English teaching will be improved by leaps and bounds.
\end{abstract}

Keywords: Artificial intelligence, College English, Teaching reform.

\section{INTRODUCTION}

In the era of artificial intelligence, technological innovation in the field of natural language is one of the most eye-catching innovation fields. The new artificial intelligence technology framework based on natural language recognition, translation, transfer and other core technologies provides a more intelligent multiple choice for the teaching and learning of language disciplines. Compared with the era of information technology, the era of artificial intelligence pays more attention to the diversity and personalization of language disciplines, which can provide higher quality technical support, resource support and mode support for teaching, so as to achieve a qualitative leap in the teaching quality of language disciplines. "Artificial intelligence technology in the field of teaching can replace the traditional teaching mode of teachers in the classroom to answer questions and solve doubts, create more space for teachers' classroom teaching, and help them get rid of the heavy teaching work. Teachers can put more energy into the cultivation of students' professional ability and quality."[1] This paper will explore the College English teaching reform in the era of artificial intelligence, in order to explore a new way of teaching reform in the new intelligent ecology, and make the artificial intelligence technology become the core support and important power source of College English teaching.

\section{THE CURRENT SITUATION OF COLLEGE ENGLISH TEACHING IN THE AGE OF ARTIFICIAL INTELLIGENCE}

In recent years, with the continuous maturity of artificial intelligence technology, especially the vigorous development of artificial intelligence technology in the field of natural language, massive intelligent applications begin to provide strong support for College English teaching. After experiencing the continuous exploration in the information age, College English teaching has finally ushered in the golden age of teaching form, teaching resources, teaching structure and teaching mode reform. From the observation of the current situation of College English development, it can be found that "the application of artificial intelligence will change the existing school running form, expand students' learning space, and help to form a student-centered learning environment" [2], and can provide teachers and students with more diversified tool support, so that they can strengthen their learning through intelligent technology when teaching and achieve a significant improvement in the quality of teaching. Both the intelligent 
software for instructional design and the intelligent tools for students' autonomous learning are profoundly changing today's College English teaching. Stanford University clearly put forward: "although quality education always needs the active participation of human teachers, AI can be used to strengthen education at all levels, especially largescale personalized education".[3] From communicating with relevant groups, it can be seen that the College English teaching reform in the era of artificial intelligence has gained two core advantages.

\subsection{Advantage of High Efficiency}

"Traditional college English teaching is often based on offline classroom teaching, and the use of artificial intelligence technology enriches the single teaching method of College English." [4] Artificial intelligence technology can provide multidirectional technical support for English learning. Intelligent scene assistance, intelligent dialogue training, intelligent language translation, intelligent voice generation and other fields have relatively perfected application system and tool system. Students can fully use these tools to assist their English learning when they are learning English. Moreover, many big platforms focusing on English teaching, English training and English training have emerged one after another. College students have a wider range of choices in English learning. They can easily improve their English level through artificial intelligence mode of English training. In College English teaching, teachers also use the corresponding platform and tools to adjust the teaching structure, so that students can get better learning experience through the application of technology.

\subsection{Personality Advantage}

English learning attaches great importance to students' personality development. In the information age, the effective realization of personality development requires both teachers and students to invest a lot of energy in the design of personality scheme. However, in the era of artificial intelligence, the personalization, customization and specialization of English learning can be realized through the comprehensive application of big data, cloud computing, artificial intelligence and other technologies. "This kind of customized learning strategy can find the weaknesses of students and automatically match the training content with the same level, effectively enhance students' learning confidence, improve learning efficiency and learning effect" [5].

\section{ANALYSIS OF COLLEGE ENGLISH TEACHING IN THE AGE OF ARTIFICIAL INTELLIGENCE}

\subsection{Lack of Teachers' Development Ability}

As can be seen from "Figure 1", only about $10 \%$ of the College English teachers interviewed said that teaching innovation is based on the application of artificial intelligence technology, and less than $3 \%$ of them have the ability to develop and apply artificial intelligence technology. Through communicating with College English teachers, we know that there is a huge difference between artificial intelligence technology and traditional information technology, and the requirement of development ability has obviously crossed many levels. It is very difficult for College English teachers to develop teaching plans, courseware or software through the use of artificial intelligence technology. The increases in difficulty have greatly hit the reform enthusiasm of College English teachers. More English teachers prefer to adopt traditional teaching methods and make up for the lack of strategy with tactical diligence, rather than devote more energy to the development and application of artificial intelligence technology. In fact, in College English teaching, there are few cases or lessons using artificial intelligence. Most of the innovation and reform of artificial intelligence teaching are the comprehensive use of traditional information technology, and the truly creative achievements of artificial intelligence technology development are still very rare. 


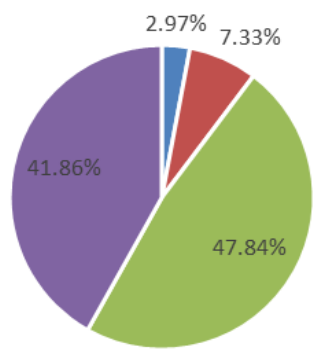

- Yes, independent development

- Yes, use for reference

- No, never

- NO,but involved

Figure 1 The proportion of College English teachers developing and using artificial intelligence technology for teaching.

\subsection{Rigid Thinking of Teachers and Students}

In the survey of teachers and students, it is found that both sides have relatively low level of recognition for the application of artificial intelligence technology. In the four basic skills of listening, speaking, reading and writing, both sides show no support for artificial intelligence technology (the specific survey results are shown in "Figure 2"). It can be seen from "Figure 2" that this phenomenon is quite common in the current college English teaching. In fact, both sides are willing to enrich the classroom situation, optimize the classroom links and increase the teaching content through information technology, but they are not willing to put more energy into the application of intelligent tools in the actual teaching. Even some teachers have a certain psychological resistance to excessive intelligent tools, and they will worry that students will use these intelligent tools to cheat, which undoubtedly limits the artificial intelligence. With the further development of intelligent technology in College English teaching, it is difficult to give full play to its unique role. This kind of rigid, obsolete and backward thinking concept is the fundamental reason that hinders the application of artificial intelligence technology in College English teaching. It is difficult to effectively reverse this unfavorable development situation only relying on the strength of teachers or students.

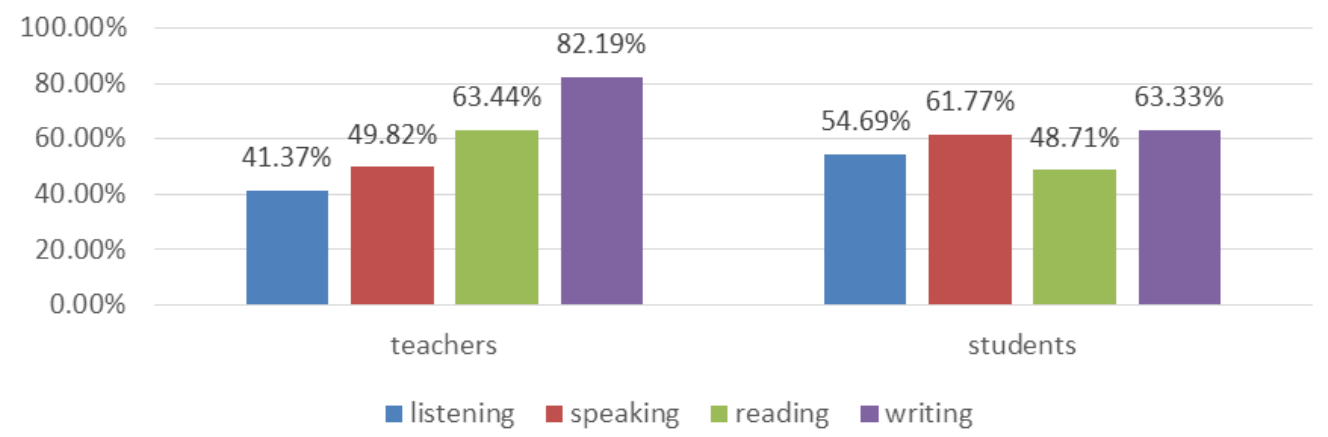

Figure 2 Distribution of teachers and students who do not support the application of artificial intelligence technology.

\subsection{Low Technical Function}

It can be seen from the survey results in "Figure $3 "$ that only $7.14 \%$ of the teachers interviewed think that the translation results given by intelligent language translation tools have certain application value, and more than $80 \%$ of the teachers interviewed still think that the translation results of intelligent language translation tools cannot reach the ideal level. From the market survey related to intelligent tools, we can also find that all kinds of artificial intelligence tools, especially those used for language learning or practice, are relatively extreme in function, showing obvious fragmental distribution, and have not formed a one-stop technical support system. Even some large English learning platforms with large scale, strong technical strength and large number of members have obvious shortcomings or gaps in technology 
provision. This phenomenon of low function of artificial intelligence technology is a typical manifestation of the early stage of the development of artificial intelligence era. This problem obviously hinders the application of artificial intelligence technology in College English teaching. It is difficult to provide more accurate and efficient technical support for the existing teaching activities and promote the deep reform of teaching mode.

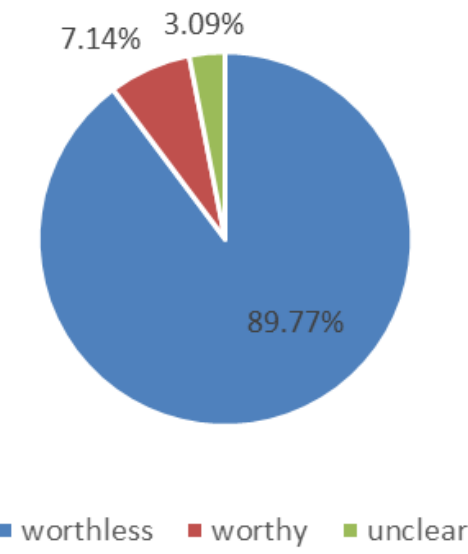

Figure 3 The results of the survey on the application value of existing English language translation tools by teachers.

\subsection{Situation Is Too Unified}

In the survey of the current problems in College English teaching, more than $70 \%$ of the students interviewed think that the current college English teaching is still mainly based on classroom teaching, and there are still obvious deficiencies in multiform innovation and personality scheme support. In communicating with English teachers, we also know that in the traditional English teaching, the concept of personality teaching is relatively perfect, but the difficulty in the implementation is relatively high. Although teachers can use traditional information technology to assist their own personality guidance and counseling, teachers still need to invest a lot of energy. Not only that, students' understanding of personalized learning is relatively vague, and they do not realize the importance of personalized learning scheme for their own development, and they do not put forward more personalized learning needs. In addition, the current college English teaching process data collection is relatively difficult, the standardization process of all kinds of technical indicators is still in the development stage, the real sense of personalized learning is difficult to be effectively implemented, which also makes the College English in the era of artificial intelligence, still need to use the traditional unified teaching method while students still use the unified progress, unified content, unified teaching mode under the restriction of unified form and unified evaluation. It has been in the low efficiency learning state for a long time, and the improvement of the overall quality of teaching has appeared obvious bottleneck.

\section{STRATEGIES OF COLLEGE ENGLISH TEACHING REFORM IN THE AGE OF ARTIFICIAL INTELLIGENCE}

\subsection{Cultural and Professional Integration, Community Development of Intelligent Achievements}

In the era of artificial intelligence, it is an objective situation that the difficulty of technology development is greatly improved. Especially in the early stage of the development of artificial intelligence, the application must face the huge difficulty of development and accept the reality that the development and the rate of return are seriously low. In the face of this unfavorable situation, if college English teaching reform wants to give full play to the advantages of artificial intelligence technology, it must break the existing teacher organization mode, introduce more experts, scholars and teachers in the field of technology through the integration of literature and professional education, and jointly establish an artificial intelligence English teaching development community with college English teachers. Through 
the cooperation of relevant parties, efforts should be made to solve the problems. According to the actual needs of College English teaching, a number of intelligent achievements aiming at the needs of English teaching have been rapidly developed. As colleges and universities have a rich talent base and high scientific research ability, College English teachers should take the initiative to put forward the needs of artificial intelligence technology reform, and develop the results together with professionals. In recent years, artificial intelligence development projects aiming at the details of College English teaching have emerged one after another, and the unique needs of teachers are being quickly met. With the gradual stability of the community structure, this development mode will be able to provide high-quality intelligent results for College English teaching. In intelligent language training, robot intelligent listening and speaking system, intelligent scene rendering and other aspects, has begun to have a certain technical foundation. College English teachers can make full use of these high-quality intelligent achievements for language learning or English learning to improve the quality of classroom teaching.

\subsection{Changing Thinking, Exploring Intelligent Mode in Big Community}

In the process of College English teaching reform, the efficient application of artificial intelligence technology must rely on the effective efforts of both teachers and students. Through the large community organization mechanism, teachers and students should pay attention to English teaching reform and the application of artificial intelligence technology. On the one hand, teachers should take the initiative to put forward the application requirements of artificial intelligence technology, show the problems in teaching design, teaching promotion, teaching management and teaching evaluation, and establish the general direction of introducing intelligent technology. On the other hand, students should make full use of their advantages of being familiar with intelligent applications and mastering more dynamic information. According to the requirements of teachers, it is necessary to take the initiative to explore and give some forward-looking application conjectures. Finally, teachers and students will work together to find a more suitable intelligent mode for College English teaching at this stage.

In the practice of College English teaching, some new models are constantly bringing forth through the help of the big community model, which produces a new model of artificial intelligence with great application value. For example, the current intelligent teaching mode of College English teaching scene creation, through the effective integration of a variety of platform resources by both teachers and students, mainly based on scene rendering, with the support of teaching resources, combined with the comprehensive application of virtual reality and other technologies, makes the scene creation in College English Teaching can be generated with one click, so that the intelligent level of the whole scene has been greatly improved. In the process of innovation of intelligent mode by both teachers and students, some traditional problems become opportunities for innovation.

In the process of strictly controlling the use of intelligent translation software, some students put forward a contrastive learning mode, which compares the results of intelligent translation with those of manual translation, so that students can deepen their grammar and application learning by finding mistakes. The first mock exam not only exerts the advantages of artificial intelligence in grammar, but also makes use of the focus training of students' error correction process, making the process of contrast learning a development process of grammar and application.

In College English teaching, a new model of dialogue teaching based on artificial intelligence is booming. Through intelligent voice dialogue, the efficiency of students' language training is greatly improved, and the efficiency of artificial intelligence is highlighted. On the whole, in the era of artificial intelligence, it will become a mainstream trend for teachers and students to explore an innovative teaching mode together. Only with the joint efforts and joint innovation of both sides, can we constantly bring forth new ideas and promote the intelligent development of College English teaching system.

\subsection{Deep Integration, Intelligent Tool Optimization in All Field}

In College English teaching, the use of intelligent tools can not only provide convenient tool support for teachers' teaching, but also provide intelligent tool support for students' English learning. However, the practical problems such as low function, fragmental distribution and changeable application direction of artificial intelligence tools restrict the comprehensive use of 
intelligent tools in College English teaching. Therefore, in the process of College English teaching reform, the optimization and integration of intelligent tools should be carried out according to the characteristics of English learning. Colleges and universities need to organize College English teachers to comprehensively screen the existing artificial intelligence tools, and evaluate the application effect of different intelligent tools, so as to finally build an intelligent tool library suitable for College English teaching.

In the process of practical teaching, students can also put forward new innovative experience of tool application according to their own learning experience or learning discovery, and add the corresponding tools to the existing tool library. Through continuous updating and iteration, they can finally provide a powerful, flexible and comprehensive intelligent tool library for both teachers and students.

At present, intelligent tools have been provided in all aspects of English teaching, including vocabulary memory, language training, writing practice, reading comprehension, application evaluation and so on. Teachers and students can flexibly choose the corresponding intelligent tool library according to the actual needs. Among them, the intelligent tool system with reading comprehension as the main service link is the most mature and the most effective. The intelligent technology that can help teachers and students solve new words, memory, review, understanding and contrast has been widely used in practical teaching and has played a very positive role.

\subsection{Personalized Guidance, Big Data Generating Intelligent Scheme}

In the reform of College English teaching, the application of artificial intelligence technology is also reflected in promoting the personalized development of teaching. English teachers should make full use of the existing information technology means to carry out data monitoring on all aspects of College English teaching, and obtain massive data of students' English learning. Students should also continuously present their own English learning process data through the use of corresponding intelligent tools, and finally establish the students' English learning ability through comprehensive analysis of various data. According to the intelligent model of English learning, this paper analyzes the students' individual learning situation deeply, and with the active fine-tuning of the teachers, generates an intelligent learning scheme for the individual, so that students can better allocate learning time, use learning resources and strengthen learning according to the scheme. In the era of artificial intelligence, the personalized process of College English learning is getting faster and faster, and students are adapting to the new learning experience mode.

\section{CONCLUSION}

"The deep integration of AI and College English teaching process will become the new normal of language teaching." [6] In practice teaching, teachers should introduce the development mode of integration of cultural courses and specialized courses according to their own lack of development abilities, and focus on the development and output of intelligent achievements according to the needs of English teaching. On this basis, teachers should actively cooperate with students to build a large community of teaching mode research, and constantly explore the application mode of artificial intelligence through the interaction, communication and cooperation between teachers and students. In addition, in practical teaching, teachers should pay attention to the construction of basic tool library, constantly enrich the system of artificial intelligence tools, so that both teachers and students can flexibly use intelligent tools to solve practical problems. Finally, teachers should promote the personalized development of English teaching, complete the big data analysis of students' learning progress through the use of corresponding tools, and then formulate personalized learning plans according to students' strengths and weaknesses, so that students can learn and complement flexibly according to the new plan, and truly promote the significant improvement of English teaching quality.

\section{AUTHORS' CONTRIBUTIONS}

This paper is independently completed by Yingchun Zhang.

\section{REFERENCES}

[1] Wang Zhenxing. Research on College English Teaching Mode Based on Artificial Intelligence [J]. Education and Teaching Research, 2020 (09): 108

[2] Li Tang. Xu Qihao. Research on English Teaching Reform under the background of 
artificial intelligence [J]. Modern communication, 2020 (02): 7

[3] STANFORD UNIVERSITY. Artificial intelligence and life in 203[EB/OL]. https: //ai100.stanford.edu/sites/g/files/sbiybj9861/f/ ai_100_report_0831 fnl.pdf

[4] Feng Jifang. The Influence of Artificial Intelligence on College English Education [J]. Heilongjiang Education, 2020 (07): 86

[5] Zhao Shengxue. College English teaching reform and strategies in the age of artificial intelligence [J]. Journal of Anshun University, 2019 (12): 76

[6] Hong Changchun. Research on the construction of ecological teaching mode of College English in the age of artificial intelligence $[\mathrm{J}]$. Audio visual foreign language teaching, 2018 (06): 33 